\title{
DESIGN AND IN VITRO CHARACTERIZATION OF FLOATING TABLETS OF METRONIDAZOLE
}

\author{
CHINNA ESWARAIAH M, JAYA S*
}

Department of Pharmaceutics, Anurag Pharmacy College, Suryapet, Telangana, India. Email: jayamay24@gmail.com

\author{
Received: 05 December 2018, Revised and Accepted: 12 January 2018
}

\begin{abstract}
Objective: The objective of the present study was to formulate the effervescent floating matrix tablet of metronidazole and to evaluate the effect of varying concentrations of hydrophilic polymers on drug release.

Methods: Drug excipients interaction was studied by Fourier transform infrared spectrophotometer. The effervescent floating matrix tablets were prepared by direct compression technique using hydroxypropyl methylcellulose (HPMCK4) and xanthan gum alone and in combination as release retardants. Microcrystalline cellulose was used as diluent. Sodium bicarbonate was used as effervescent agent. The prepared matrix tablets were evaluated for their physicochemical parameters such as weight variation, hardness, friability, content uniformity, buoyancy time, and in vitro dissolution.

Results: Micromeritic properties and post-compression parameters were evaluated and all the parameters were found within the acceptable limit. The drug release data were subjected to different models to evaluate release kinetics and mechanism of drug release. The matrix tablets prepared with xanthan gum and a mixture of xanthan gum and HPMCK4 were retarded the drug release up to $12 \mathrm{~h}$. The release mechanism of metronidazole was evaluated on the basis of release exponent $n$ value in Peppas model. The $n$ value of the formulations ranged from 0.46 to 0.89 which indicated Case II transport and zero-order release.
\end{abstract}

Conclusion: Floating matrix tablet is the simple, efficient, and economic method to sustain the release of metronidazole to eradicate Helicobacter pylori in peptic ulcer disease.

Keywords: Floating matrix tablets, Metronidazole, Xanthan gum, Helicobacter pylori.

(C) 2019 The Authors. Published by Innovare Academic Sciences Pvt Ltd. This is an open access article under the CC BY license (http://creativecommons. org/licenses/by/4. 0/) DOI: http://dx.doi.org/10.22159/ajpcr.2019.v12i3.31018

\section{INTRODUCTION}

Oral route is the most convenient route for the drug delivery due to low cost of the therapy, ease of administration leads to high level of patient compliance and flexibility in the designing of dosage form. Novel oral drug delivery systems classified into oral controlled release dosage forms (OCRDFs) and targeting dosage forms [1]. Variable and short gastric residence time results in decreased efficacy of the administered dose when administered in the form of OCRDF. To improve the performance of OCRDF, a new concept was discovered by scientists in drug delivery that is gastroretentive drug delivery systems (GRDDSs). A GRDDS can be defined as a system which remains in the stomach for a sufficient time period against all the physiological barriers, releasing the active moiety in a controlled manner and finally becomes metabolized in the body. Gastroretentive drug delivery system can be a useful tool in delivery of drugs that are primarily absorbed in the duodenum that is upper part of the gastrointestinal tract [2]. Floating drug delivery is the class of targeted oral drug delivery system. A floating drug delivery system floats in the gastric juice without affecting the gastric emptying rate. This technique can provide therapeutically effective plasma drug concentration for longer durations, thereby reducing the dosing frequency and minimizing fluctuations and also helps to increase a drug's gastric residence time and reduces the variability in bioavailability [3].

Helicobacter pylori (Campylobacter pylori) is a Gram-negative, microaerophilic bacterium, usually found in the stomach or the upper part of the small intestine. H. pylori infection is a common worldwide infection that is an important cause of peptic ulcer disease and gastric cancer. Peptic ulcers are sores that develop in the lining of the stomach (gastric ulcers), lower esophagus (esophageal ulcers), and/or first part of the small intestine (duodenal ulcers), as a result of inflammation caused by the bacteria H. pylori, erosions, and stomach acids. American
College of Gastroenterology guidelines, 2017 for the treatment of H. pylori infection includes the following therapeutic strategies for the first-line treatment, bismuth, proton-pump inhibitors, tetracyclines, and a nitroimidazole (strong recommendation), particularly in those with previous macrolide exposure or are penicillin allergic [4]. Nitroimidazole (metronidazole) antibiotics are most active antibiotics for the treatment and prevention of infections caused by anaerobic bacteria. Metronidazole is used as an antibiotic, amebicide, and antiprotozoal agent. Metronidazole used for preparing floating tablets, to retain in the stomach, because it is locally active in the gastric mucosa. The prolonged effect of locally active metronidazole increases its clinical efficacy for better eradicating $H$. pylori in peptic ulcer disease [5-9].

Drug release from the matrix tablets was controlled by the polymer properties and its structure. Hydrophilic polymers are one of the most commonly used drug release retardants in matrix tablets. Hydroxypropyl methylcellulose (HPMCK4) is a semi-synthetic watersoluble cellulose derivative. It has been widely used in the development of sustained release dosage forms. Natural gums are inert and non-toxic. Xanthan gum is a natural, biosynthetic, edible, and high-molecularweight gum. Xanthan gum is an extracellular polysaccharide produced by fermentation of carbohydrate with Xanthomonas campestris bacteria, is hydrophilic swellable polymer. The primary structure of xanthan gum consists of 1,4 linked $\beta$-D-glucose residues, having a trisaccharide side chain of $\beta$-D-mannose- $\beta$-D-glucuronic acid- $\alpha$-D-mannose attached to alternate D-glucose units of the main chain. The anionic character of this polymer is due to the presence of both glucuronic acid and pyruvic acid groups in the side chain. It develops a weak structure in water which creates high viscosity solutions at low concentration $[10,11]$.

The objective of the present study was to prepare the effervescent floating matrix tablets of metronidazole using hydrophilic polymers 
such as hydroxypropyl methylcellulose, xanthan gum alone, and in combination. Sodium bicarbonate was used as gas generating agent to float and to achieve sustained release of metronidazole to eradicate H. pylori in the treatment of peptic ulcer.

\section{MATERIALS AND METHODS}

\section{Materials}

Metronidazole was purchased from Yarrow Chemical Ltd., Mumbai, India. Xanthan gum, hydroxypropyl methylcellulose K4M, microcrystalline cellulose, and sodium bicarbonate were purchased from Vijaya Enterprises Ltd., Hyderabad, India; magnesium stearate and talc were purchased from Aman Scientific Traders, Vijayawada, India. All other reagents, chemicals, and solvents used were of analytical grade.

\section{Methods}

\section{Drug-excipient compatibility study}

Infrared spectra of the pure drug and drug with polymers were recorded on a Fourier transform infrared spectrophotometer. The disc method was employed to study possible interactions between drug and selected polymers. Infrared spectrum was taken by scanning the sample in $\mathrm{KBr}$ (IR grade) discs and analyzed over a wavenumber range of $4000-400 \mathrm{~cm}^{-1}$. Transmittance spectra were recorded.

\section{Preparation of floating matrix tablets}

Floating matrix tablets of metronidazole were prepared by direct compression technique. All the ingredients were individually screened through sieve no. 60 except glidant and lubricant. Required quantities of metronidazole, polymer, diluents, and sodium bicarbonate were accurately weighed according to the composition shown in Table 1 and mixed in a polybag for about 30-45 min. The obtained blend was lubricated with talc and magnesium stearate for another $5 \mathrm{~min}$, and then, the resultant mixture was directly compressed into tablets with $12 \mathrm{~mm}$ flat faced circular punches using 12-station rotary tablet machine (CEMACH, Ahmedabad, India) [12]

\section{Micromeritic properties of blended powder}

Angle of repose

The frictional forces in a loose powder can be measured by the angle of repose. Angle of repose is defined as maximum angle possible between the surface of a pile of the powder and the horizontal plane. The angle of repose was determined by the fixed funnel method. The accurately weighed powder was taken in a funnel. Angle of repose was calculated using the following equation [13]:

$\tan \theta=\mathrm{h} / \mathrm{r}$

Where, $\theta=$ Angle of repose,

$\mathrm{h}=$ Height of the pile, $\mathrm{cm}$

$\mathrm{r}=$ Radius of the base of the pile, $\mathrm{cm}$.
Carr's consolidation index

The Carr's consolidation index of the powder blend is defined as:

$$
\text { Carr's consolidation index }=\frac{\text { Tapped density }- \text { bulk density }}{\text { Tapped density }} \times 100
$$

Bulk density is the ratio of mass of powder to the bulk volume. Tapped density is the ratios of mass of powder to the tapped volume.

\section{Evaluation of matrix tablets}

The tablets were evaluated for their physical properties such as weight variation, hardness, and friability.

Weight variation

A total of 20 tablets of each formulation were selected randomly and weighed individually using an electronic weighing balance. The average weight was calculated and individual tablet weight was compared with average weight [14]

Hardness and friability

Hardness studies were carried out by a Monsanto hardness tester. Six determinations were carried out for each sample to calculate the hardness of prepared tablets. Hardness of tablets was measured in terms of $\mathrm{kg} / \mathrm{cm}^{2}$. The friability of the tablets was measured using Roche friabilator. 10 tablets were weighed accurately, placed in the chamber, and rotated for $4 \mathrm{~min}$ (100 rotations). At the end, the dust on the tablet were cleaned, weighed accurately again and the percent friability was computed from the weight of tablets. Friability was calculated using the following equation [15]:

$$
\text { Friability }=\frac{\text { Initial weight }- \text { Final weight }}{\text { Initial weight }} \times 100
$$

Uniformity of drug content

A total of 10 tablets were weighed from each formulation and triturated in mortar to a fine powder. Powder equivalent to $200 \mathrm{mg}$ of metronidazole was extracted in $100 \mathrm{ml}$ of $0.1 \mathrm{~N}$ hydrochloric acid and filtered. The drug content was determined by measuring the absorbance of sample using ultraviolet (UV)-visible spectrophotometer (LAB INDIA) at $277 \mathrm{~nm}$ after appropriate dilution with $0.1 \mathrm{~N}$ hydrochloric acid. The drug content was determined using calibration curve [16].

\section{Buoyancy lag time determination}

The buoyancy of the tablets was studied at $37 \pm 0.5^{\circ} \mathrm{C}$, in $100 \mathrm{ml} 0.1 \mathrm{~N}$ hydrochloric acid. The time required for the tablet to rise to the surface and total floating time was recorded [17]

In vitro dissolution study

Dissolution test of floating matrix tablets of metronidazole was performed using a USP type II (paddle) dissolution testing apparatus. The rotational speed was set at $50 \mathrm{rpm}$ and the temperature remained constant at $37 \pm 0.5^{\circ} \mathrm{C} .900 \mathrm{ml}$ of $0.1 \mathrm{~N}$ hydrochloric acid was used as dissolution medium. $5 \mathrm{ml}$ aliquots were withdrawn at predetermined

\begin{tabular}{|c|c|c|c|c|c|c|c|c|c|}
\hline \multirow[t]{2}{*}{ Composition (mg/tab) } & \multicolumn{9}{|c|}{ Formulation } \\
\hline & F1 & F2 & F3 & F4 & F5 & F6 & F7 & F8 & F9 \\
\hline Metronidazole & 200 & 200 & 200 & 200 & 200 & 200 & 200 & 200 & 200 \\
\hline Xanthan gum & - & - & - & 125 & 150 & 175 & 62.5 & 75 & 87.5 \\
\hline Sodium bicarbonate & 65 & 65 & 65 & 65 & 65 & 65 & 65 & 65 & 65 \\
\hline MCC & 100 & 75 & 50 & 100 & 75 & 50 & 100 & 75 & 50 \\
\hline Magnesium stearate & 5 & 5 & 5 & 5 & 5 & 5 & 5 & 5 & 5 \\
\hline Talc & 5 & 5 & 5 & 5 & 5 & 5 & 5 & 5 & 5 \\
\hline Total weight & 500 & 500 & 500 & 500 & 500 & 500 & 500 & 500 & 500 \\
\hline
\end{tabular}

Table 1: Composition of floating matrix tablets of metronidazole

HPMCK4M: Hydroxypropyl methylcellulose, MCC: Microcrystalline cellulose 
time intervals and the same amount of fresh dissolution medium added to maintain the sink conditions. The collected samples were filtered through a $0.45 \mu \mathrm{m}$ membrane filter and the concentration of dissolved drug was measured at $277 \mathrm{~nm}$ using a UV-visible spectrophotometer (LABINDIA). Cumulative percentage of drug release was calculated using equation obtained from a calibration curve [18]

Kinetic analysis of drug release data

To study the release mechanism of metronidazole from the sustained release floating matrix tablets, the in vitro drug release data were fitted into the following the mathematical models:

$\begin{array}{lll}\text { - } & \text { Zero order } & \mathrm{Q}_{\mathrm{t}=} \mathrm{Q}_{0}+\mathrm{k}_{0} \mathrm{t} \\ \text { - } & \text { First order } & \log \mathrm{C}=\log \mathrm{C}_{0}-\mathrm{k}_{1} \mathrm{t} / 20303 \\ \text { - } & \text { Korsmeyer-Peppas } & \mathrm{Q}_{\mathrm{t}}=\mathrm{k}_{\mathrm{h}} \mathrm{t}^{1 / 2} \\ \text { - } & \text { Hixon-Crowell cube root } & \mathrm{Q}_{\mathrm{t}} / \mathrm{Q}_{\alpha}=\mathrm{k}_{\mathrm{p}} \mathrm{t}^{\mathrm{n}} \\ & \left(\mathrm{W}_{0}^{1 / 3}-\mathrm{W}_{\mathrm{t}}^{1 / 3}\right)=\mathrm{k}_{\mathrm{h}} \mathrm{t}\end{array}$

Where, $\mathrm{Q}_{0}, \mathrm{Q}_{\mathrm{t}}$ and $\mathrm{Q}$ are the amounts of drug dissolved initially, at time $\mathrm{t}$ and at time infinite. $\mathrm{C}_{0}$ and $\mathrm{C}$ are the concentrations of drug initially and at time $t, W_{0}$ and $W_{t}$ are the amounts of drug in the pharmaceutical dosage form initially and at time $\mathrm{t}$, and $\mathrm{k}_{0,} \mathrm{k}_{1}, \mathrm{k}_{\mathrm{h}}$, and $\mathrm{k}_{\mathrm{p}}$ refer to the rate constants obtained from the linear curves of the respective models. $n$ is the diffusional exponent that characterizes the mechanism of drug release. The values of the coefficient were calculated using regression analysis between $\log Q_{t} / Q_{\alpha}$ and $\log$ time. The diffusional exponent $n$ value was obtained from the slope of the regression equation and $\mathrm{k}_{\mathrm{p}}$ was calculated from antilog of the intercept value.

If the value of $\mathrm{n}$ for a cylinder is $<0.45$, it suggests the Fickian release (diffusion controlled), if $\mathrm{n}>0.45$ and $<0.89$, it is non-Fickian release (diffusion and polymer relaxation), 0.89 is Case II release (only relaxation and swelling) and $>0.89$ it suggests super Case II release (relaxation and erosion) for swellable systems.

For cylindrical systems like tablets, the $\mathrm{n}$ values of 0.45 and 0.89 represent pure diffusion or erosion release, respectively [19].

\section{RESULTS AND DISCUSSION}

\section{Micromeritic properties of blended powder}

The powder mixture of all the formulations was evaluated for angle of repose, bulk density, tapped density, and compressibility index. Powder blend indicated good flow properties with an angle of repose values ranging from $29.20 \pm 0.82$ to $32.08 \pm 0.75^{\circ}$. The Carr's compressibility index for all the formulations was found to be between $13.31 \pm 0.3^{\circ}$ and $18.77 \pm 0.5 \%$

\section{Evaluation of physical parameters}

Sustained release floating matrix tablets of metronidazole were prepared by direct compression technique employing varying concentrations of HPMCK4, xanthan gum alone, and in combination. The physical properties of metronidazole floating matrix tablets were given in Table 2. Sustained release floating matrix tablets of metronidazole were prepared by direct compression technique. A total of nine formulations were prepared. The tablet weight variation, hardness, friability, and content uniformity for each formulation are shown in Table 2 . The weight variation test indicated that the percentage deviation of all tablet formulations was found to be within pharmacopoeial acceptable limit. The hardness of all the tablets was within the range of $3.32 \pm 0.14-4.59 \pm 0.15 \mathrm{~kg} / \mathrm{cm}^{2}$. The percentage weight loss in the friability test was found to be below $0.8 \%$ in all the cases indicated that all the tablets had good mechanical strength. The drug content in all the batches was determined by measuring the absorbance of sample at $277 \mathrm{~nm}$ using double-beam UV spectrophotometer (LABINDIA). The content uniformity among different formulations was found to be higher and the drug content was more than $98 \%$ which indicates uniform drug distribution in all the formulations.

\section{In vitro floating properties}

The in vitro buoyancy studies in simulated gastric fluid revealed good buoyancy for all the formulations. Buoyancy lag time for all the tablets are shown in table 3 was found to be $<2 \mathrm{~min}$. Sodium bicarbonate was used as effervescent agent. On contact with the acidic medium, the fluid permeates into the tablet, which generates carbon dioxide. The gas generated is trapped and protected within the gel, formed by hydration of polymer, thus decreasing the density of the tablet. As the density of the tablet falls below 1, the tablet becomes buoyant. All the tablets (F4-F9) floated in pH 1.2 buffer solution for more than $12 \mathrm{~h}$, except formulations with HPMCK4 (F1-F3).

Effect of polymer concentration on matrix integrity of the tablets Maintenance of matrix integrity of the tablets is an important parameter that needs to be studied because if the tablet does not maintain its physical integrity, it could be broken down into smaller fragments and escape from the gastrointestinal tract. In the present study, metronidazole has been formulated into sustained release floating tablet to release drug in the gastric environment to show its local action in the treatment of peptic ulcer. Buoyancy studies indicated that HPMCK4 alone could not maintain matrix integrity up to $12 \mathrm{~h}$ and disintegrated completely after $6 \mathrm{~h}$ as well as rapid erosion of the tablet was observed when placed in the dissolution medium due to its low viscosity. However, when combined with xanthan gum, it can control the release of drug and also matrix integrity was maintained up to $12 \mathrm{~h}$.

\section{In vitro dissolution study}

Metronidazole release from the floating matrix tablets was studied for $12 \mathrm{~h}$ in $0.1 \mathrm{~N}$ hydrochloric acid. Total nine formulations were made with hydroxypropyl methylcellulose $\mathrm{K} 4$ and xanthan gum alone and in combination. Polymers employed in different ratios, i.e., 1:0.625 (25\%), 1:0.75 (30\%), and 1:0.875 (35\%). The results of dissolution studies indicated that the burst release was observed with hydroxypropyl methylcellulose. Sustained release was observed with xanthan gum alone and its combination with HPMCK4. Formulation (F4) containing $25 \%$ of xanthan gum as release retardant was selected as best. The comparative drug release profiles are given in Fig. 1. Metronidazole release from all the matrix tablets was dependent on the concentration of release retardant contained in the tablet. The drug release from the matrix tablets was decrease as the concentration of release retardant was increased. HPMCK4 alone could not control the release

Table 2: Physical properties of floating matrix tablets of metronidazole

\begin{tabular}{lllll}
\hline $\begin{array}{l}\text { Formulation } \\
\text { code }\end{array}$ & $\begin{array}{l}\text { Weight } \\
\text { variation }^{\#}\end{array}$ & Hardness* $^{*}$ & Friability & $\begin{array}{l}\text { Content } \\
\text { uniformity }\end{array}$ \\
\hline F1 & $497.30 \pm 1.36$ & $3.32 \pm 0.14$ & $0.72 \pm 0.24$ & $98.23 \pm 1.32$ \\
F2 & $499.42 \pm 1.13$ & $3.54 \pm 0.16$ & $0.69 \pm 0.16$ & $99.20 \pm 1.28$ \\
F3 & $498.76 \pm 1.26$ & $3.58 \pm 0.12$ & $0.70 \pm 0.18$ & $99.64 \pm 1.34$ \\
F4 & $498.90 \pm 1.06$ & $4.59 \pm 0.15$ & $0.56 \pm 0.12$ & $98.26 \pm 1.35$ \\
F5 & $498.64 \pm 1.32$ & $4.78 \pm 0.10$ & $0.66 \pm 0.11$ & $99.05 \pm 1.34$ \\
F6 & $497.45 \pm 1.16$ & $3.46 \pm 0.16$ & $0.64 \pm 0.13$ & $98.19 \pm 1.26$ \\
F7 & $498.82 \pm 1.09$ & $4.52 \pm 0.14$ & $0.72 \pm 0.13$ & $99.56 \pm 1.32$ \\
F8 & $499.85 \pm 1.28$ & $4.38 \pm 0.12$ & $0.69 \pm 0.09$ & $98.94 \pm 1.23$ \\
F9 & $498.64 \pm 1.09$ & $4.22 \pm 0.13$ & $0.71 \pm 0.10$ & $99.56 \pm 1.20$ \\
\hline
\end{tabular}

\#,*All values are expressed as mean \pm SD, ${ }^{*} \mathrm{n}=20$ and ${ }^{*} \mathrm{n}=6$. SD: Standard deviation

Table 3: Buoyancy study of floating matrix tablets of metronidazole

\begin{tabular}{llll}
\hline $\begin{array}{l}\text { Formulation } \\
\text { code }\end{array}$ & $\begin{array}{l}\text { Floating lag } \\
\text { time (min) }\end{array}$ & $\begin{array}{l}\text { Floating } \\
\text { time (h) }\end{array}$ & $\begin{array}{l}\text { Matrix } \\
\text { integrity }\end{array}$ \\
\hline F1 & $<1$ & $<12$ & - \\
F2 & $<1$ & $<12$ & - \\
F3 & $<1$ & $<12$ & - \\
F4 & $>12$ & + \\
F5 & $<2$ & $>12$ & + \\
F6 & $<1$ & $>12$ & + \\
F7 & $<1$ & $>12$ & + \\
F8 & $<2$ & $>12$ & + \\
F9 & $<2$ & $>12$ & + \\
\hline
\end{tabular}


of metronidazole from the tablets because the amount of polymer was not sufficient to maintain the matrix integrity due to its low molecular weight and viscosity. Xanthan gum could control the release of metronidazole up to $12 \mathrm{~h}$ due to its high molecular weight. These results indicate that xanthan gum has higher drug retarding ability than HPMCK4. The presence of xanthan gum alone and in combination with HPMCK4 retarded the initial release of drug from the tablets due to high swelling property.

\section{Drug release kinetics}

The release data of matrix tablets were fitted into various mathematical models (zero order, first order, Higuchi, ancd Peppas) to evaluate the kinetics and mechanism of drug release from the tablets. The model that best fits the release data is selected based on the correlation coefficient value in various models. The model that gives high $\mathrm{R}^{2}$ value considered as the best fit of the release data. The $\mathrm{R}^{2}$ values in zero, first order, Higuchi-Peppas, and Hixson-Crowell models are given in Table 4 . The results indicated that the drug release from the matrix tablets followed zero-order kinetics. To evaluate the drug release mechanism from the matrix tablets plots of percent drug released versus square root of time as per Higuchi's equation, log time versus log percentage of drug release as per Peppas and time versus cube root of drug remained as per Hixson-Crowell were constructed. When the release data were analyzed as per Peppas equation, the release exponent $n$ value

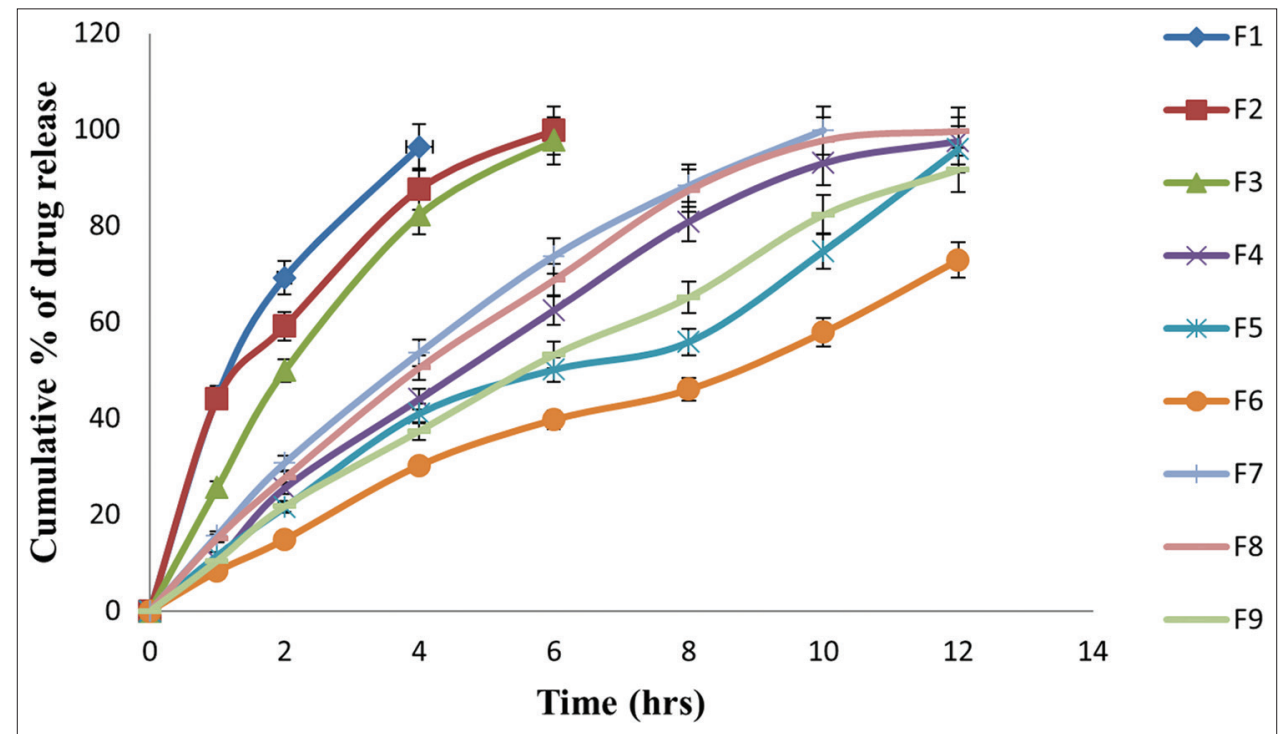

Fig. 1: Comparative in vitro dissolution profile of all the formulations mean \pm standard deviation, $n=3$

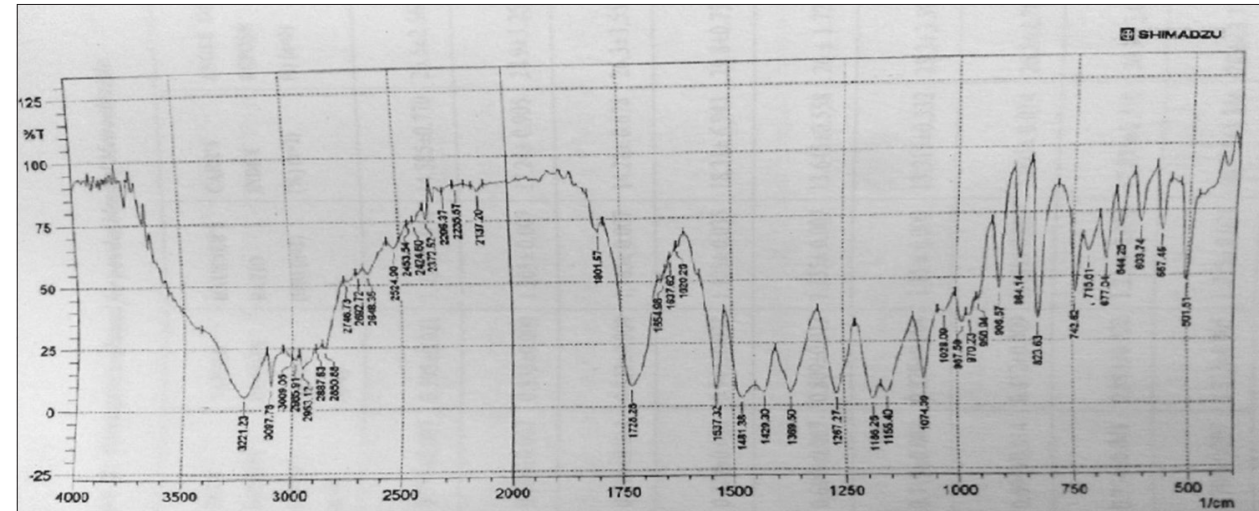

a

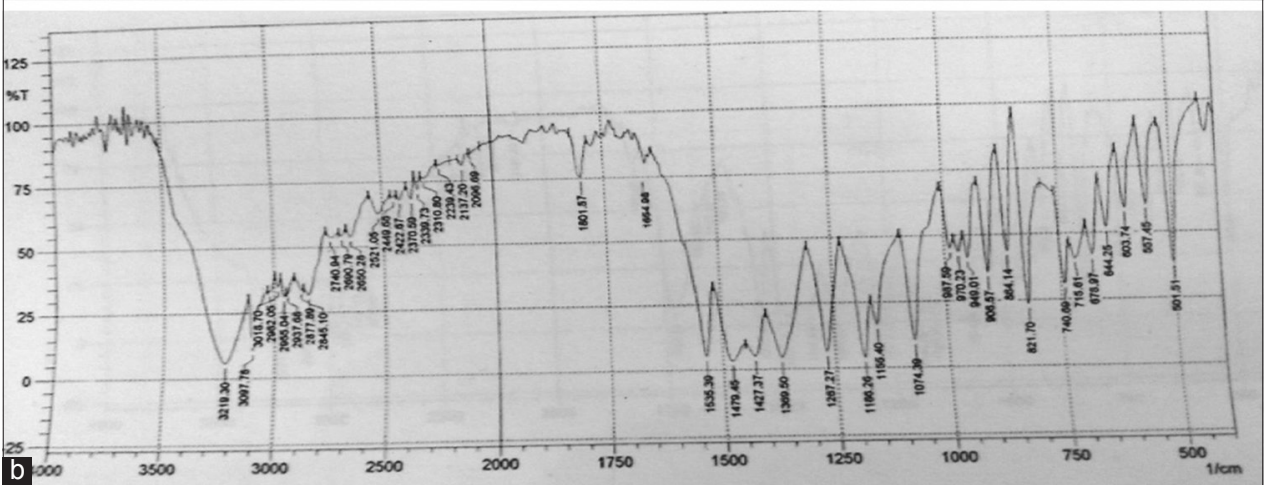

Fig. 2: (a) Fourier-transform infrared spectroscopy spectrum of pure metronidazole. (b): Fourier-transform infrared spectroscopy spectrum of floating matrix tablets of metronidazole (F4) 
Table 4: Correlation coefficients (R) values of drug release kinetics and mechanism of floating matrix tablets of metronidazole

\begin{tabular}{|c|c|c|c|c|c|c|}
\hline \multirow[t]{2}{*}{ Formulation } & \multirow[t]{2}{*}{ Zero order } & \multirow[t]{2}{*}{ First order } & \multirow[t]{2}{*}{ Higuchi } & \multicolumn{2}{|c|}{ Peppas } & \multirow[t]{2}{*}{ Hixson-Crowell } \\
\hline & & & & $\mathbf{R}^{2}$ & $\mathbf{n}$ & \\
\hline F1 & 0.826 & 0.971 & 0.975 & 0.957 & 0.46 & 0.990 \\
\hline F3 & 0.953 & 0.949 & 0.973 & 0.979 & 0.75 & 0.996 \\
\hline F4 & 0.976 & 0.890 & 0.962 & 0.983 & 0.89 & 0.979 \\
\hline F5 & 0.979 & 0.781 & 0.936 & 0.988 & 0.80 & 0.890 \\
\hline F6 & 0.989 & 0.959 & 0.944 & 0.994 & 0.85 & 0.978 \\
\hline F7 & 0.975 & 0.761 & 0.971 & 0.994 & 0.80 & 0.944 \\
\hline F8 & 0.955 & 0.896 & 0.970 & 0.990 & 0.78 & 0.983 \\
\hline F9 & 0.992 & 0.938 & 0.955 & 0.996 & 0.86 & 0.980 \\
\hline
\end{tabular}

Table 5: Data of Fourier transform infrared spectra of pure and best formulation

\begin{tabular}{|c|c|c|c|}
\hline Functional group & Characteristic peak/ $\mathbf{c m}^{-1}$ & Observed peaks-pure drug/ $\mathrm{cm}^{-1}$ & Observed peaks-best formulation $/ \mathrm{cm}^{-1}$ \\
\hline \multicolumn{4}{|l|}{ NO (stretching) } \\
\hline Symmetric & $1375-1385$ & 1369.50 & 1369.50 \\
\hline Asymmetric & $1475-1550$ & 1535.39 & 1535.39 \\
\hline $\mathrm{C}=\mathrm{C}$ (stret) aromatic & $1450-1600$ & 1479.45 & 1479.45 \\
\hline C-N (stret) imidazole & $1100-1230$ & 1155.40 & 1157.33 \\
\hline O-H (stret) alcoholic & $3200-3550$ & 3219.30 & 3219.30 \\
\hline $\mathrm{C}=\mathrm{N}$ (stret) imidazole & $1640-1690$ & 1654.98 & 1653.05 \\
\hline
\end{tabular}

was $\leq 0.89$ with all the tablets indicating Case II release, i.e., polymer swelling and relaxation might be the mechanism for the drug release from the matrix tablets.

\section{Compatibility studies}

From the Fourier-transform infrared spectroscopy studies shown in Fig. 2, it is very clear that there are no interactions between drug and excipients. All the peaks responsible for the active functional groups were present in the best formulation (F4). The characteristic and observed peaks are mentioned in Table 5 .

\section{CONCLUSION}

The effervescent floating matrix tablets of metronidazole were prepared by direct compression method employing HPMCK4, xanthan gum as drug release retardants, and sodium bicarbonate used as gas generating agent. The concentration of gas generating agent and release retardants considerably affected the buoyancy time, matrix integrity, and profile of drug release. Thus, by changing the concentration of gas generating agent and polymer in formulations, the characterization of the matrix tablets could be controlled. All the formulations showed floating lag time $<2$ min. Xanthan gum alone and in combination with HPMCK4 has successfully sustained the release of metronidazole. The drug release from the floating matrix tablets was found to be zeroorder kinetics with Case II transport, involves polymer swelling and chain relaxation as mechanism of drug release. Floating tablets of metronidazole sustained the drug release for $12 \mathrm{~h}$ can be expected to eradicate $H$. pylori in peptic ulcer disease.

\section{ACKNOWLEDGMENT}

The authors are thankful to the principal and management of Anurag Pharmacy College, for providing necessary facilities to carryout this work.

\section{CONFLICTS OF INTEREST}

Authors have no conflicts of interest in publishing this research work.

\section{AUTHORS' CONTRIBUTION}

All the authors have contributed equally.

\section{REFERENCES}

1. Vyas SP, Roop KK. Controlled Oral Administration. Controlled Drug Delivery. New Delhi, India: Vallabh Prakashan; 2012. p. 156-7.

2. Pawar VK, Kansal S, Garg G, Awasthi R, Singodia D, Kulkarni GT, et al. Gastroretentive dosage forms: A review with special emphasis on floating drug delivery systems. Drug Deliv 2011;18:97-110.

3. Arora S, Ali J, Ahuja A, Khar RK, Baboota S. Floating drug delivery systems: A review. AAPS PharmSciTech 2005;6:E372-90.

4. Asnaashari S, Khoei NS, Zarrintan MH, Adibkia K, Javadzadeh Y. Preparation and evaluation of novel metronidazole sustained release and floating matrix tablets. Pharm Dev Technol 2011;16:400-7.

5. William DC, Grigorios IL, Colin WH, Steven FM. ACG clinical guideline: Treatment of Helicobacter pyroli infection. Am J Gastroenterl 2017;112:212-38.

6. Loh ZC, Elkordy AA. Formulation and evaluation of different floating tablets containing metronidazole to target stomach. Curr Drug Deliv 2015; $12: 425-43$.

7. Sakonjan T, Satit P, Tasana P, Srisagul S. Development of curcumin floating tablets based on low density foam powder. Asian J Pharm Sci 2016;2:130-1.

8. Amritha V, Suriner K, Krishnahari P. Formulation and in vitro evaluation of floating tablets of HPMCK4M and carbapol934P using metronidazole as a model drug. Int J Pharm Sci Res 2014;5:2244-9.

9. Harshal S, Chetan G, Surbhi U, Sujit P. Development and in vitro evaluation of an oral floating tablet of metfronidazole. J Drug Deliv Ther 2018;8:83-6.

10. Denise FS. Xanthan gum: A versatile biopolymer for biomedical and technological applications. J Appl Polym Sci 2015;132:42035-48.

11. Atif A, Iqbal M, Naveed A, Haji MS, Aftab U, Minahaj U, et al. Assessment of xanthan gum based sustained release matrix tablets containing highly water soluble propranolol HCL. Acta Pol Pharm Drug Res 2013;70:283-9.

12. Jaya S, Chowdary KP, Rajeswararao P. Enhancement of dissolution rate and formulation development of ritonavir tablets by solid dispersion technology. Int J Pharm Ther 2013;4:51-8.

13. Aulton ME. Aulton's Pharmaceutics. The Design and Manufacture of Medicines. $4^{\text {th }}$ ed. Edinburgh: Churchill Livingstone; 2013. p. $187-98$.

14. Jaya S, Amala V. Formulation and in vitro evaluation of oral disintegrating tablets of amlodipine besylate. Int J Appl Pharm 2019;11:49-54.

15. Jaya S, Chowdary KP, Rajeswararao P. Effect of superdisintegrants and solubilizers on the dissolution rate and dissolution efficiency of 
ritonavir tablets. Int Res J Pharm Appl Sci 2012;2:224-9.

16. Mahendar G, Jaya S. Formulation and evaluation of floating tablets of salbutamol sulphate. Int Res J Pharm Appl Sci 2012;2:97-109.

17. Rabi NP, Susanta KP, Prabhakar RV. Formulation and in vitro evaluation of combined floating-bioadhesive tablets of imatinib mesylate. Int J Pharm Pharm Sci 2017;9:27-33.
18. Laila HE, Aya RA, Ahmed A, Ashmawy E, Nadia MM. Preparation and evaluation of metronidazole sustained release floating tablets. Int $\mathrm{J}$ Pharm Pharm Sci 2014;6:198-204.

19. Jaya S, Srilaxmi G. Formulation and in-vitro characterization of ambroxol hydrochlotide sustained release matrix tablets. Int J Pharm Sci Res 2019;10:1000-6. 